\title{
Variability in the Calcium Phosphate Concretion Load in the Kidney of Mercenaria mercenaria
}

\author{
Kenneth Gold ${ }^{1}$, Gerard Capriulo ${ }^{2}$ and Kevin Keeling ${ }^{3}$ \\ 'Department of Biology, City College, City University of New York, New York, N.Y. 10031, USA \\ ${ }^{2}$ Marine Sciences Research Center, State University of New York, Stony Brook, N.Y. 11790, USA \\ ${ }^{3}$ Department of Biology, Brooklyn College, City University of New York, Brooklyn, N.Y. 11210, USA
}

\begin{abstract}
Appreciable differences in calcium phosphate concretion loads were found between different size classes of the hard clam Mercenaria mercenaria. The largest (thickness, $\geqslant 41.3 \mathrm{~mm}$ ) had significantly higher amounts of concretions than either the intermediate $(36.5-41.2 \mathrm{~mm})$ or smallest (25.4-36.4 mm) clams. Comparison of the concretion weights in clams of comparable size from 2 selected sites showed that clams from restricted areas had significantly higher loads than those from approved beds.
\end{abstract}

Mollusks have a tendency to deposit concretions in their kidneys (Potts, 1967). There are no conclusive studies as yet on the biological sigificance of this material, which has recently been identified in a variety of species as amorphous calcium phosphate (Doyle et al., 1978; Carmichael et al., 1979; Tiffany, 1979; George et al., 1980). Doyle and co-workers recovered approximately $2.8 \mathrm{~g}$ of concretions from about 400 Mercenaria mercenaria, an average yield, therefore, of $7.0 \mathrm{mg}$ per clam. Tiffany (1979) noted the appearance of Macrocallista nimbosa, suggesting that the abundance of concretions in that species was high. The kidney of Tridacna crocea also contains numerous calcium phosphate granules (Gold, 1980).

Edible Mercenaria mercenaria, collected from a single site in Bayport, Long Island, New York, were sorted according to size: thickness $\supseteq 41.3 \mathrm{~mm}$ (oldest); 36.5 to $41.2 \mathrm{~mm}$ (intermediate); and 25.4 to $36.4 \mathrm{~mm}$ (youngest). Size is a good index to age when clams are collected at a single site.

The other collection sites were Horseshoe Cove, Sandy Hook, N. J. and Wards Point, Staten Island, N. Y., where the clams were unsuitable for consumption. Only intermediate and older clams were collected at these 2 locations, and size and age are not necessarily correlated in these samples,

The concretions were isolated by enzymatic digestion of the kidney tissue. We used the filtrate of a $2.5 \%$ aqueous suspension of powdered trypsin (Trypsin
1-100, hog pancreas, ICN, Inc.); $\mathrm{pH}, 7.8$; temperature, $40^{\circ} \mathrm{C}$; volume, $10 \mathrm{ml}$; and intervals up to $5 \mathrm{~h}$ as needed with intermittent agitation. The brownish-black concretions promptly sedimented; the supernatant was then removed by suction and the granules washed repeatedly with distilled $\mathrm{H}_{2} \mathrm{O}$. The concretions were stored in absolute ethanol, and later - after drying weighed in an electrobalance (Cahn, Model G). The

Table 1. Mercenaria mercenaria. Weights (mg) of concretions in kidney. $\bar{Y}$ mean; s standard deviation

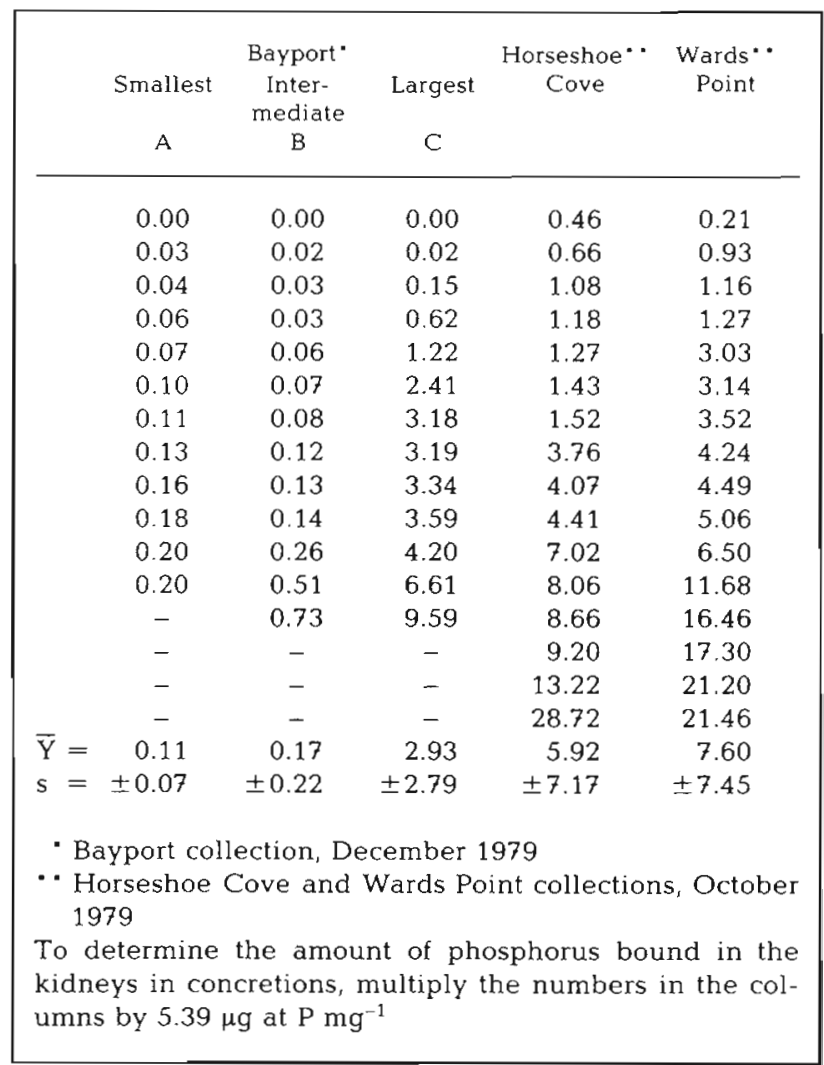


weights of kidney concretions from all locations are given in Table 1 . Specimens were also analyzed in a JEOL JSM-35U scanning electron microscope equipped with a Kevex energy dispersive x-ray detector.

Single classification analysis of variance (ANOVA) was used to test for significant differences among concretion weights as a function of age (only for the Bayport clams where there is correlation between age and size) and location. Data were transformed [log (100 $\mathrm{Y}+1)$ ] to meet the ammumptions of ANOVA. Bartlett's test was employed to certify homogeneity of variance of the transformed data. A. priori planned comparisons were also carried out.

Results of ANOVA indicated that there were significant differences $(P<0.001)$ in concretion weights with age (Columns $\mathrm{A}, \mathrm{B}$, and $\mathrm{C}$ of Table 1 ). The a priori comparisons show that the largest have significantly higher weights of concretions $(P<0.001)$ than either the smallest or intermediates. Comparison of the largest Bayport clams (Column C) with the largest plus intermediate clams from Horseshoe Cove and Wards Point, showed significant differences $(\mathrm{P}<0.06)$. The $a$ priori comparisons indicated that the oldest Bayport clams had lower weights of concretions than either the Horseshoe Cove $(\mathrm{P}<0.09)$ or Wards Point clams $(\mathrm{P}<0.05)$.

The concretion weights from Horseshoe Cove and Wards Point clams compare closely with the value calculated from the data of Doyle and co-workers $\left(7.0 \mathrm{mg} \mathrm{clam}{ }^{-1}\right)$. The lower mean weights of concretions from the Bayport intermediate and older clams support Doyle's et al. hypothesis that environmental

Table 2. Mercenaria mercenaria. Total mean reactive phosphorus content in kidney concretions of individuals from 3 habitats ( $\mu \mathrm{g}$ at $\mathrm{P} / \mathrm{mg}^{-1}$ concretions). $\mathrm{n}$ sample size ${ }_{i} \overline{\mathrm{Y}}$ mean $_{;} \overline{\mathrm{Y}}$ grand mean for all locations; s standard deviation

\begin{tabular}{|ccc|}
\hline Bayport & Horseshoe Cove & Wards Point \\
\hline$\overline{\mathrm{Y}}=4.32$ & $\overline{\mathrm{Y}}=5.98$ & $\overline{\mathrm{Y}}=5.39$ \\
$\mathrm{n}=12$ & $\mathrm{n}=18$ & $\mathrm{n}=15$ \\
$\mathrm{~s}=2.22$ & $\mathrm{~s}=0.44$ & $\mathrm{~s}=0.97$ \\
$\overline{\mathrm{Y}}=5.39 \pm 1.49$ & & \\
\hline
\end{tabular}

factors may alter concretion formation. The published values for dissolved inorganic phosphorus (DIP) concentrations show that the restricted regions sampled had high levels of phosphorus (average $\approx 2.0 \mu \mathrm{g}$ at $\mathrm{Pl}^{-1}$; Duedall et al., 1979), whereas the Great South Bay has relatively lower levels (average, $0.51 \mu \mathrm{g}$ at $\mathrm{Pl}^{-1}$; Hair and Buckner, 1978). Seasonal variability in these values is at most only a factor of 2 at both locations, with the values in the restricted region consistently higher than in the Great South Bay area.

Portions of the isolated concretions $(10 \mathrm{mg})$ were dissolved in a mixture of acids (Horwitz, 1965). The $\mathrm{pH}$ of the solution was raised to 7.0 to 8.0 prior to determining the reactive phosphorus content (Strickland and Parsons, 1972).

Total phosphorus concentration varied from $\approx 2-7 \mu \mathrm{g}$ at $P \mathrm{mg}^{-1}$ kidney concretions (Table 2). This value appears to be approximately constant; the grand mean $(\overline{\bar{Y}})$ for all locations is $5.39 \pm$ a standard deviation of 1.49. Chemically and morphologically the concretions were similar to those analyzed by Doyle et al. (1979) for Mercenaria mercenaria.

The mean phosphorus concentration reported here (5.39 $\pm 1.49 \mu \mathrm{g}$ at $\mathrm{P} \mathrm{mg}^{-1}$ of concretions) compares closely with the phosphorus content in granules extracted from other species. The granules from 2 preparations of Pecten maximus contained 6.7 and $5.2 \mu \mathrm{g}$ at $\mathrm{P} \mathrm{mg}^{-1}$ (Table 3 of George et al., 1980); Argopecten irradians concretions yielded $\approx 4.5 \mu \mathrm{g}$ at $\mathrm{P} \mathrm{mg}^{-1}$ (Table 4 of Carmichael et al., 1979); both Tridacna crocea and Nautilus pompilius concretions yielded $\approx 5.0 \mu \mathrm{g}$ at $\mathrm{P} \mathrm{mg}^{-1}$ (Gold, 1980).

The ecological significance of molluscan concretion production extends to other trophic levels in the form of a phosphorus sink. Phosphorus bound in the form of concretions is removed from the water column and is unavailable to the suspended biological community. The magnitude of the sink in Great South Bay was estimated by examining the relationship of concretion phosphorus to the total dissolved inorganic phosphorus, using (a) data from Tables 1 and 2; (b) the estimated density of Mercenaria mercenaria (WAPORA, Inc., 1979); and (c) the value $0.51 \pm 0.20 \mu \mathrm{g}$ at $\mathrm{P}^{-1}$ dissolved inorganic phosphorus (Hair and Buckner, 1973). Summing the 3 size categories given for

Table 3. Mercenaria mercenaria. Estimated density (clams $\mathrm{m}^{-2}$ ) in Great South Bay, Long Island, New York. Data from WAPORA, Inc. (1979). P = average concentration of phosphorus in units of $\mu \mathrm{g}$ at $\mathrm{P} \mathrm{m}^{-2}$ of bay bottom for appropriate size class of clam. s standard deviation

\begin{tabular}{lccccrc}
\hline & Babylon & Islip & Brookhaven & mean & s \\
\hline Little necks & 2.2 & 2.3 & 3.3 & $2.60 \pm 0.60$ & 1.402 \\
Cherrystones & 1.1 & 1.0 & 0.5 & $0.88 \pm 0.33$ & 0.792 \\
Chowders & 1.4 & 0.7 & 0.1 & $0.73 \pm 0.65$ & 11.540 \\
\hline
\end{tabular}


clam density in Table 3 , we estimate that $\approx 14 \mu \mathrm{g}$ at $\mathrm{P} \mathrm{m}^{-2}$ was present in Great South Bay as kidney concretions, i.e. roughly $3 \%$ of the total DIP load in the Bay or $3.3 \times 10^{3} \mathrm{~g}$ at $\mathrm{P}$.

\section{LITERATURE CITED}

Carmichael, N. G., Squibb, K. S., Fowler, B. A. (1979). Metals in the molluscan kidney: a comparison of two closely related bivalve species (Agropecten), using x-ray microanalysis and atomic absorption spectroscopy. J. Fish. Res. Bd Can. 36: 1149-1155

Doyle, L. J., Blake, M. J., Woo, C. C., Yevich, P. (1978). Recent biogenic phosphorite: concretions in mollusk kidneys. Science, N. Y. 199: 1431-1433

Duedall, J. W., O'Connors, H. B., Wilson, R. E., Parker, J. H. (1979). The lower bay complex, Marine Ecosystems Analysis Project, N. Y. Bight Atlas, Monograph 29

George, S. G., Pirie, B. J. S., Coombs, T. L. (1980). Isolation and elemental analysis of metal-rich granules from the kidneys of the scallop. Pecten maximus (L.). J. exp. mar. Biol. Ecol. 42: 143-156

Gold, K. (1980). Studies on calcium phosphate concretions in the kidneys of marine mollusks: structure, phosphorus and trace mineral content. Abstracts, Am. Soc. Limnol. Oceanogr.

Hair, M. E., Buckner, S. (1973). An assessment of the water quality characteristics of Great South Bay and contiguous streams. Regional Marine Recources Council, NassauSuffolk Regional Planning Board

Horwitz, W. (1965). Official methods of analysis of the association of official agricultural chemists, The Collegiate Press, Menasha, Wisconsin

Potts, W. T. W. (1967). Excretion in the mollusks. Biol. Rev. 41: $1-41$

Strickland, J. D. H., Parsons, T. R. (1972). A practical handbook of seawater analysis. Fish. Res. Bd Can., Ottawa, Canada

Tiffany, III, W. J. (1979). Analysis of renal calculi from a marine mollusk (Macrocallista nimbosa): implications for the study of urolithiasis. Invest. Urology 17: 164-165

WAPORA, Inc. (1979). Estuarine impact assessment (shellfish resources) for the Nassau-Suffolk stream flow augmentation alternatives. Unpubl. manuscript, prepared for U. S. Environmental Protection Agency, Region 2, New York, Contract No. 68-01-4616

Accepted for printing on July 8, 1982 